\title{
PRODUÇÃO E DESENVOLVIMENTO DE MUDAS DE EUCALIPTO EM FUNÇÃO DE DOSES DE FÓSFORO
}

\author{
José Henrique Tertulino Rocha ${ }^{1 *}$, Maurício Reynaldo Pietro², Karla Borelli ${ }^{1}$, Clarice Backes ${ }^{3}$, Monica Bernardo Neves ${ }^{4}$ \\ *Autor para correspondência: josehrocha@bol.com.br
}

\begin{abstract}
RESUMO: No presente trabalho, objetivou-se avaliar o efeito de doses de fósforo (P) na qualidade de mudas clonais de Eucalyptus urophylla $\mathrm{x}$ Eucalyptus grandis no viveiro e a sobrevivência e desenvolvimento inicial no campo. O delineamento experimental utilizado foi o inteiramente casualizado com 4 tratamentos e 5 repetições, com 30 plantas por repetição. Ao final do ciclo (90 dias), foram utilizadas 15 mudas para a determinação do acúmulo de massa seca e concentração de nutrientes na parte aérea e o restante foi plantado no campo para determinar o percentual de sobrevivência e o desenvolvimento inicial. Os tratamentos foram compostos por 4 doses de adubação fosfatada $\left(0,0 ; 1,3 ; 2,6\right.$ e 5,2 $\left.\mathrm{mg} \mathrm{planta}^{-1}\right)$. Para a obtenção de mudas de qualidade em condiçoes semelhantes a desse experimento, devem ser utilizados doses de $\mathrm{P}$ na faixa de 3,6 a 3,8 mg planta ${ }^{-1}$. Doses superiores a $4 \mathrm{mg} \mathrm{planta}^{-1}$ prejudicam $^{-1}$ o desenvolvimento e a qualidade das mudas de eucalipto. A adubação fosfatada adequada em mudas de eucalipto aumenta em $30 \%$ o percentual de sobrevivia das mudas no campo.
\end{abstract}

Palavras-chave: Nutrição de plantas, adubação fosfatada, sobrevivência de mudas no campo.

\section{PRODUCTION AND DEVELOPMENT OF EUCALYPTUS SEEDLINGS IN FUNCTION OF DOSES OF PHOSPHORUS}

\begin{abstract}
This study evaluated the effect of phosphorus $(P)$ on the survival in the nursery and early development in the field of clonal Eucalyptus urophylla $x$ Eucalyptus grandis seedlings. The experimental design was completely randomized with four treatments and five replicates of 30 plants per replicate. At the end of the cycle (90 days), 15 seedlings were used for determining the dry matter accumulation and nutrient concentration in the shoot. The rest was planted in the field to determine the percentage of survival and early development. The treatments consisted of four doses of P fertilization (0.0, 1.3, 2.6 and $\left.5.2 \mathrm{mg} \mathrm{plant}^{1}\right)$. To obtain high quality seedlings in conditions similar to this experiment it is required doses of $P$ in the range from 3.6 to $3.8 \mathrm{mg} \mathrm{plant}^{1}$. Doses greater than $4 \mathrm{mg}_{\text {plant }}{ }^{-1}$ affect the development and quality of eucalyptus seedlings. An adequate phosphorus fertilization of eucalyptus seedlings increase, by about $30 \%$, the percentage of surviving seedlings in the field.
\end{abstract}

Key words: Plant nutrition, fertilizer, phosphate, plant survival in the field,

\section{INTRODUÇÃO}

O setor florestal no Brasil vem se expandindo a cada ano, destacando-se a produção de celulose, com aumento de 4,5\% em 2010. Com este crescimento, o setor vem tomando maior importância na economia, sendo responsável por $3,7 \%$ do total das exportações no ano de 2010 (ASSOCIAÇÃO BRASILEIRA DE PRODUTORES DE FLORESTA PLANTADA - ABRAF, 2011). Para manter o crescimento acelerado é necessário expandir o plantio de espécies para fins comerciais, bem como aumentar a produtividade das florestas. $\mathrm{O}$ gênero Eucalyptus se torna cada vez mais importante, por apresentar espécies de alta produtividade, ciclo reduzido e alta flexibilidade às condições edafoclimáticas, sendo o gênero mais plantado em todo mundo (GONÇALVES et al., 2008).
Para se obter florestas de alto padrão, vários fatores devem ser considerados, sendo um dos principais a qualidade das mudas utilizadas no plantio, apresentandose bem desenvolvidas, vigorosas, resistentes ao estresse do transplante e livre de pragas e doenças, assegurando boa adaptação e crescimento após o plantio (CRUZ et al., 2004). A obtenção de mudas de boa qualidade exige a utilização de substrato que forneça os nutrientes necessários ao pleno desenvolvimento da planta (CECONI et al., 2007). Quando isso não ocorre, a fertilização se torna uma atividade indispensável, sendo considerado um dos fatores mais importantes para garantir um bom desenvolvimento das mudas (ASSENHEIMER, 2009). A correta nutrição consistiu-se em fator essencial para o crescimento das mudas em altura, diâmetro produção de biomassa (CECONI et al., 2006) e para o estabelecimento de florestas de alta produtividade (SILVA et al., 2004).

\footnotetext{
'Escola Superior de Agricultura "Luiz de Queiroz" - Piracicaba, São Paulo, Brasil

${ }^{2}$ Faculdade de Agronomia e Engenharia Florestal - Garça, São Paulo, Brasil

${ }^{3}$ Universidade Estadual de Goiás - São Luis de Montes Belos, Goiás, Brasil

${ }^{4}$ Sucocítrico Cutrale Ltda - Araraquara, São Paulo, Brasil
}

Cerne, Lavras, v. 19, n. 4, p. 535-543, out./dez. 2013 
Dentre os nutrientes essenciais, o $\mathrm{P}$ apresenta grande importância na produção de mudas de eucalipto, sendo considerado um dos nutrientes que mais limita o crescimento das mudas na fase inicial de produção (GRACIANO et al., 2006). Por participar dos chamados compostos ricos de energia, como o trifosfato de adenosina (ATP), o P possui papel fundamental na vida das plantas, sendo essencial na divisão celular, reprodução e no metabolismo vegetal (fotossíntese, respiração e síntese de substâncias orgânicas) (MALAVOLTA, 1985). A deficiência de P nas fases de indução e formação das raízes, reduz, significativamente, o comprimento das mesmas (SCHAWAMBACH et al., 2005), implicando em queda na qualidade das mudas.

Pelo exposto, neste trabalho, objetivou-se avaliar o efeito da aplicação de doses de P na qualidade de mudas clonais de Eucalyptus urophylla x Eucalyptus grandis no viveiro e sua sobrevivência e desenvolvimento inicial no campo.

\section{MATERIAL E MÉTODOS}

\subsection{Local}

O presente trabalho foi realizado no Centro de Produção de Mudas Clonais de Eucalipto da Faculdade de Agronomia e Engenharia Florestal de Garça (FAEF), localizado nas coordenadas $22^{\circ} 13^{\prime} 31^{\prime \prime} \mathrm{S}$ e $49^{\circ} 40^{\prime} 21^{\prime \prime} \mathrm{W}$ e 600 metros de altitude. O clima predominante é de verão quente e úmido e inverno seco, com precipitação média anual de $1300 \mathrm{~mm}$ e temperatura média anual de $22^{\circ} \mathrm{C}$.

$\mathrm{O}$ experimento foi conduzido em duas etapas: produção de mudas no viveiro e desenvolvimento no campo. Foram utilizadas estacas de um clone híbrido de Eucalyptus urophylla com E. grandis.

\subsection{Delineamento experimental}

O delineamento experimental utilizado foi o inteiramente casualizado com 4 tratamentos, 5 repetições e 30 plantas por repetição. Ao final do ciclo (90 dias), foram utilizadas 15 mudas para a determinação do acúmulo de massa seca e concentração de nutrientes na parte aérea e o restante foi plantado no campo para determinar o percentual de sobrevivência e o desenvolvimento inicial. Portanto, para essas avaliações, foram utilizadas 5 repetições, com 15 plantas por repetição.

Os tratamentos foram constituídos por doses de

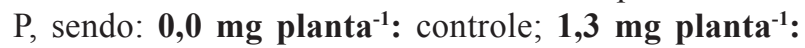
$1,02 \mathrm{mg}_{\text {planta }}{ }^{-1}$ na adubação de base $\left(20,43 \mathrm{~g} \mathrm{~m}^{-3} \mathrm{de} \mathrm{P}\right) \mathrm{e}$ 0,$05 ; 0,09 ; 0,14 \mathrm{mg} \mathrm{planta}^{-1}$ nas três adubações de cobertura
(25; 45; $70 \mathrm{mg} \mathrm{L}^{-1}$ respectivamente); 2,6 mg planta $^{-1}$ : 2,04 $\mathrm{mg}_{\text {planta }}{ }^{-1}$ na adubação de base $\left(40,86 \mathrm{~g} \mathrm{~m}^{-3} \mathrm{de} \mathrm{P}\right) \mathrm{e}$ 0,$10 ; 0,18 ; 0,28 \mathrm{mg} \mathrm{planta}^{-1}$ nas três adubações de cobertura (50; 90; $140 \mathrm{mg} \mathrm{L}^{-1}$ respectivamente); e 5,2 mg planta $^{-1}$ : $4,08 \mathrm{mg}$ planta $^{-1}$ na adubação de base $\left(81,74 \mathrm{~g} \mathrm{~m}^{-3} \mathrm{de} \mathrm{P}\right) \mathrm{e}$ 0,$20 ; 0,36 ; 0,56 \mathrm{mg}$ planta $^{-1}$ nas três adubações de cobertura (100; 180; $240 \mathrm{mg} \mathrm{L}^{-1}$ respectivamente).

A adubação de base foi efetuada utilizando como fonte de $\mathrm{P}$ o super fosfato simples em pó, incorporado no substrato. As adubações de cobertura foram realizadas aos 40, 60 e 85 dias após o plantio, via fertirrigação (lâmina de $4 \mathrm{~mm}$ ) onde aplicou-se as diferentes doses de P via fosfato monoamônico e os demais nutrientes necessários para o desenvolvimento das mudas (Tabela 1) As fontes utilizadas para fornecerem os demais nutrientes são: Sulfato de Amônio, Cloreto de Potássio, Nitrato de Cálcio e Sulfato de Magnésio. A solução de micronutrientes foi composta por $15 ; 2 ; 0,6 ; 3,25 ; 0,1 ; 1,15$ e $0,4 \mathrm{mg} \mathrm{L}^{-1}$ de $\mathrm{Fe}, \mathrm{B}, \mathrm{Cu}$, $\mathrm{Mn}, \mathrm{Mo}, \mathrm{Zn}$ e Co respectivamente.

Tabela 1 - Concentração dos nutrientes da solução utilizadas nas adubações de cobertura.

Table 1 - Concentration of nutrients of solution used in fertilization coverage.

\begin{tabular}{cccc}
\hline & \multicolumn{3}{c}{ Concentração } \\
\cline { 2 - 4 } Nutrientes & \multicolumn{3}{c}{ Dias após o plantio } \\
\cline { 2 - 4 } & 40 & 60 & 85 \\
\hline N & 450 & 750 & 300 \\
K & 450 & 750 & 1200 \\
Ca & 450 & 750 & 1200 \\
Mg & 150 & 250 & 400 \\
S & 150 & 250 & 400 \\
Sol. Micro & 0,6 & 1 & 1,6 \\
\hline
\end{tabular}

Para a produção das mudas foram utilizadas estacas de 5 a $7 \mathrm{~cm}$ e com 3 a 4 pares de folhas reduzidas a $50 \%$, colocadas em tubetes de $50 \mathrm{~cm}^{3}$ com substrato composto de casca de pinus compostada e fibra de coco, na proporção de 1:1 (v:v). Após o estaqueamento, os tubetes permaneceram por um período de 30 dias na casa de vegetação, recebendo irrigações periódicas por microasperção, com intervalos de 30 minutos, durante todo o dia. Após esse período, as mudas passaram para a casa de sombra, onde permaneceram cobertas com uma tela de sombreamento de $50 \%$, por um período de oito

Cerne, Lavras, v. 19, n. 4, p. 535-543, out./dez. 2013 
dias, recebendo irrigações diárias de $9 \mathrm{~mm}$ (divididas em 8 irrigações) e posteriormente foram espaçadas na bandeja a $25 \%$ de ocupação e transferidas para uma área a pleno sol, onde permaneceram por um período de 52 dias, recebendo irrigações diárias de $12 \mathrm{~mm}$ (divididas em 4 irrigações).

Terminada a fase de produção, 50\% das mudas foram instaladas no campo, em solo classificado como Argissolo Vermelho Amarelo distrófico, cujas características químicas são apresentadas na Tabela 2 .

Tabela 2 - Resultado da análise química inicial do solo, na camada de 0-20 cm, antes do plantio das mudas.

Table 2 - Results of the initial soil chemical analysis, at 0-20 $\mathrm{cm}$, before planting the seedlings.

\begin{tabular}{ccccccccccc}
\hline $\mathrm{pH}$ & $\mathrm{M} . \mathrm{O}$. & $\mathrm{P}_{\text {resina }}$ & $\mathrm{H}+\mathrm{Al}$ & $\mathrm{K}$ & $\mathrm{Ca}$ & $\mathrm{Mg}$ & $\mathrm{SB}$ & $\mathrm{CTC}$ & $\mathrm{V} \%$ \\
\hline $\mathrm{CaCl}_{2}$ & $\mathrm{~g} \mathrm{dm}^{-3}$ & $\mathrm{mg} \mathrm{dm}^{-3}$ & ----------- & $\mathrm{mmol}_{\mathrm{c}}$ & $\mathrm{dm}^{-3}$ & --------- & $\%$ \\
\hline 4,5 & 8 & 11 & 32 & 0,7 & 8 & 3 & 12 & 44 & 27 \\
\hline
\end{tabular}

Para o preparo do solo, adotou-se o sistema de cultivo mínimo, onde se realizou a dessecação das plantas daninhas e o sulcamento na profundidade de $0,35 \mathrm{~m}$.

De acordo com a análise do solo, foi efetuada a calagem com calcário dolomítico, para atingir a saturação por bases recomendadas para a cultura que é de $60 \%$ (RAIJ et al., 1997). Na adubação de plantio aplicou-se $12 \mathrm{~kg} \mathrm{ha}^{-1}$ de $\mathrm{N} ; 70 \mathrm{~kg} \mathrm{ha}^{-1}$ de $\mathrm{P}_{2} \mathrm{O}_{5}$ e $8 \mathrm{~kg} \mathrm{ha}^{-1}$ de $\mathrm{K}_{2} \mathrm{O}$. Foram realizadas duas adubações de cobertura, aos 30 e aos 60 dias após o plantio no campo, adicionando $24 \mathrm{~kg} \mathrm{ha}^{-1}$ de $\mathrm{N}$ e $16 \mathrm{~kg} \mathrm{ha}^{-1}$ de $\mathrm{K}_{2} \mathrm{O}$ em cada uma delas. A calagem foi efetuada em uma faixa de um metro sobre a linha de plantio, a adubação de base foi efetuada em coveta lateral, e a adubação de cobertura foi aplicada em superfície. As fontes de N, P e K foram uréia, superfosfato simples e cloreto de potássio, respectivamente. Não foram efetuadas irrigações no período de pós plantio.

\subsection{Características avaliadas}

O desenvolvimento e a qualidade das mudas no viveiro foram analisados por meio dos parâmetros morfológicos e nutricionais: altura, diâmetro do colo, percentual de enraizamento e aproveitamento das mudas, acúmulo de matéria seca da parte aérea e raiz, concentração e acúmulo de nutrientes na parte aérea.

As determinações de altura das mudas e diâmetro do caule foram realizadas aos 40, 60 e 90 dias após o estaqueamento (DAE). As medidas dos diâmetros foram feitas na altura do colo, e as alturas foram obtidas do nível do substrato até a gema apical. O percentual de enraizamento foi obtido pela contagem das mudas enraizadas no final do período de permanência na casa de vegetação e o percentual de aproveitamento pela contagem das mudas aptas ao plantio no final do ciclo (90 dias).

Aos 90 DAE, utilizaram-se 50\% das mudas formadas de cada repetição para a determinação do acúmulo de massa seca e concentração e acúmulo de nutrientes na parte aérea. Após a retirada dos tubetes, procedeu-se a lavagem do sistema radicular, separando as mudas em parte aérea e raiz, as quais foram secas em estufa de circulação forçada de ar por 72 horas a $65^{\circ} \mathrm{C}$. Após a determinação da massa seca, a parte aérea foi moída e enviada para o Laboratório de Nutrição de Plantas da Faculdade de Ciências Agronômicas (FCA) para a determinação da concentração de macro e micronutrientes, de acordo com a metodologia descrita por Malavolta et al. (1997). O acúmulo de nutrientes pelas mudas foi obtido por meio do produto da concentração de nutrientes pela quantidade de matéria seca da parte aérea.

O percentual de sobrevivência no campo foi obtido pela contagem das mudas que sobreviveram nos primeiros 30 dias de plantio e o desenvolvimento inicial foram obtidos também por parâmetros morfológicos, medindo-se a altura e o diâmetro do colo mensalmente, por um período de três meses.

\subsection{Análise dos dados}

Os resultados foram submetidos à análise de variância, utilizando o software SISVAR versão 4.2 (FERREIRA, 2003). Os resultados das doses foram ajustados à regressão linear e quadrática.

\section{RESULTADOS E DISCUSSÃO}

A produção e desenvolvimento das mudas de eucalipto apresentaram comportamento diferenciado de acordo com a dose de P aplicada, conforme apresentado a seguir:

\subsection{Desenvolvimento e qualidade das mudas no viveiro}

\subsubsection{Características morfológicas}

As doses de P não influenciaram significativamente o percentual de enraizamento das mudas, que, em média, foi de $94 \%$. Para as variáveis altura e diâmetro houve influência dos tratamentos somente aos 60 e 90 DAE.

Cerne, Lavras, v. 19, n. 4, p. 535-543, out./dez. 2013 
Aplicando uma curva de resposta do crescimento das mudas em altura e diâmetro em função das doses de $\mathrm{P}$ aplicadas, observa-se que a equação polinomial de segunda ordem representou, significativamente, os dados $(\mathrm{p}<0,05)$, para ambos os casos, sendo a dose estimada de $3,6 \mathrm{mg}$ planta $^{-1}$, que resultou nos maiores valores de altura e diâmetro aos 90 DAE (Figuras 1 e 2).

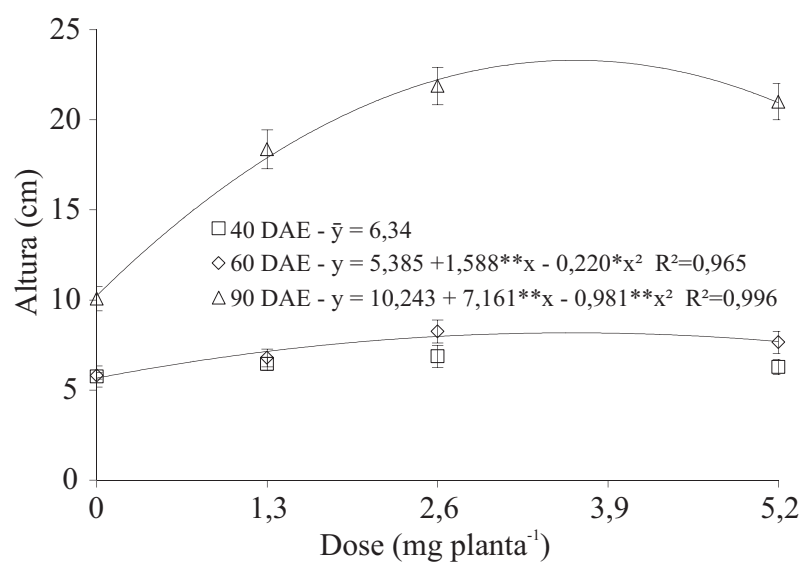

Figura 1 -Altura de mudas de eucalipto em função das doses de P realizadas aos 40; 60 e 90 dias após o estaqueamento (DAE). As barras significam o erro padrão da média do intervalo de dados.

Figure 1 - Height of eucalyptus as a function of $P$ rates performed at 40, 60 and 90 days after cutting (DAE). The bars mean the standard deviation of the data interval.

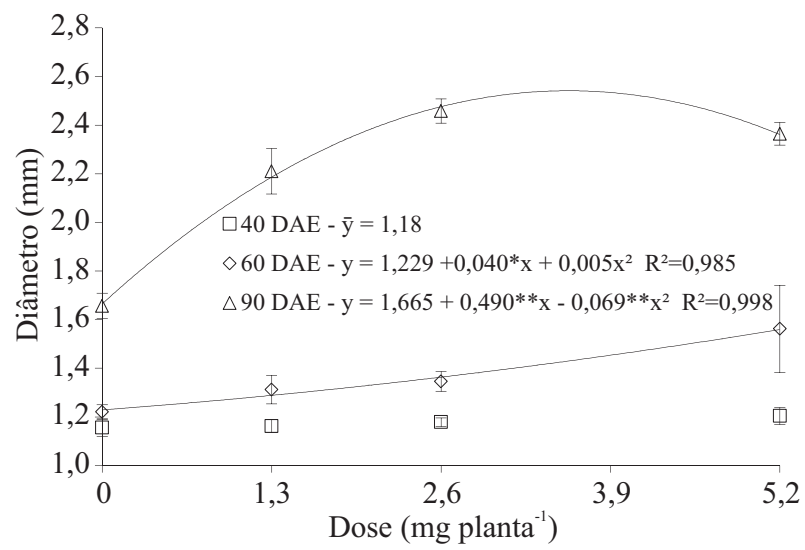

Figura 2 - Diâmetro do coleto de mudas de eucalipto em função das doses de P realizadas aos 40; 60 e 90 dias após o estaqueamento (DAE). As barras significam o erro padrão da média do intervalo de dados.

Figure 2 - Stem diameter of eucalyptus seedlings according to the levels of P measured 40, 60 and 90 days after cutting (DAE). The bars mean the standard deviation of the data interval.
Esse comportamento também foi evidenciado por Avila (2008), trabalhando com o mesmo híbrido, porém com doses maiores ( 0 a $\left.52 \mathrm{mg}_{\text {planta }}{ }^{-1}\right)$. $\mathrm{O}$ fato de menores doses terem apresentados bons resultados neste estudo, quando comparado ao de Avila (2008), é explicado, em razão do parcelamento da adubação efetuada no presente trabalho, que reduz as perdas de nutrientes, visto o tamanho reduzido dos recipientes $\left(50 \mathrm{~cm}^{3}\right)$. Segundo Xavier et al. (2009), na expedição para o campo as mudas devem ter de 20 a $40 \mathrm{~cm}$ de altura e diâmetro do coleto maior que 2,0 $\mathrm{mm}$. Esses valores foram alcançados a partir da dose de $1,8 \mathrm{mg}$ planta $^{-1} \mathrm{de}$ P. Doses inferiores não proporcionaram bom desenvolvimento, visto que a deficiência de P reduz o desenvolvimento radicular, resultando em menor aproveitamento da água e dos nutrientes contidos no substrato, além de diminuir a absorção e transporte do $\mathrm{N}$ (ARAÚJO; MACHADO, 2006). Avila (2008) obteve mudas com altura média de $18,5 \mathrm{~cm}$ e diâmetro do como e $2,5 \mathrm{~mm}$, com a dose de $17,5 \mathrm{mg} \mathrm{planta}^{-1} \mathrm{de}$ P. A adubação fosfatada também aumentou o desenvolvimento de mudas de outras espécies florestais, como o Luehea divaricata (CECONI et al., 2006), Parapiptadenia rígida (SCHUMACHER et al., 2004) e Psidium guajava (CORRÊA et al., 2003).

A relação altura diâmetro (H/D) avaliada aos 90 dias após o plantio, apresentou mudanças significativas em função das doses de P. Essa relação foi representada significativamente $(p<0,01)$ por uma equação quadrática, onde a maior relação foi obtida com a dose estimada de 3,7 $\mathrm{mg} \mathrm{planta}^{-1}$ (Figura 3).

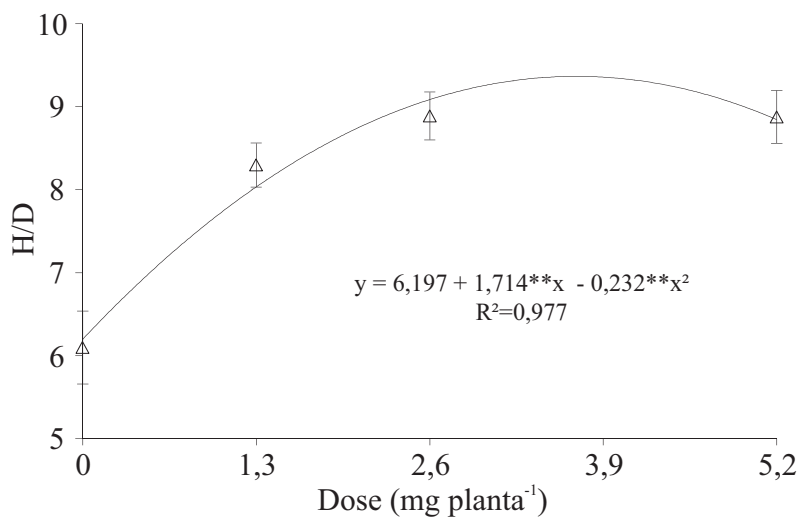

Figura 3 - Relação H/D de mudas de eucalipto em função das doses de $\mathrm{P}$ determinada aos 90 dias após o estaqueamento. As barras significam o erro padrão da média do intervalo de dados.

Figure $3-H / D$ ratio of eucalyptus as a function of $P$ rates determined at 90 days after striking. The bars indicate the standard deviation of the data interval.

Cerne, Lavras, v. 19, n. 4, p. 535-543, out./dez. 2013 
A relação H/D constitui um dos parâmetros usados para avaliar a qualidade de mudas florestais, pois, além de refletir o acúmulo de reservas, assegura maior resistência e melhor fixação no solo e, por esse motivo, quanto menor for essa variável maior a capacidade de sobrevivência dessa muda no campo (CARNEIRO, 1995). O fato da elevação dessa relação com o aumento da dose de $\mathrm{P}$ até a dose de 3,7 $\mathrm{mg}$ planta $^{-1}$ (Figura 3) explica-se em decorrência de $\mathrm{P}$ apresentar relação sinérgica com o N (ARAÚJO; MACHADO, 2006), e, com isso doses altas de $\mathrm{P}$ fizeram aumentar a absorção do N, confirmado por meio das análises foliares (ver item 3.1.2), fazendo com que as mudas desenvolvessem mais em altura, elevando essa relação. Os valores encontrados nesse estudo foram bem menores que os observados por Gomes et al. (2003).

Para a massa seca da parte aérea, sistema radicular e massa seca total das mudas verificou-se também a influência das doses de P com comportamento quadrático. As doses estimadas que proporcionaram os máximos valores foram de $3,7 \mathrm{mg}$ planta $^{-1}$ para a parte aérea, $3,4 \mathrm{mg}_{\text {planta }}{ }^{-1}$ para o sistema radicular e $3,6 \mathrm{mg}$ planta $^{-1}$ para a massa seca total (Figura 4).

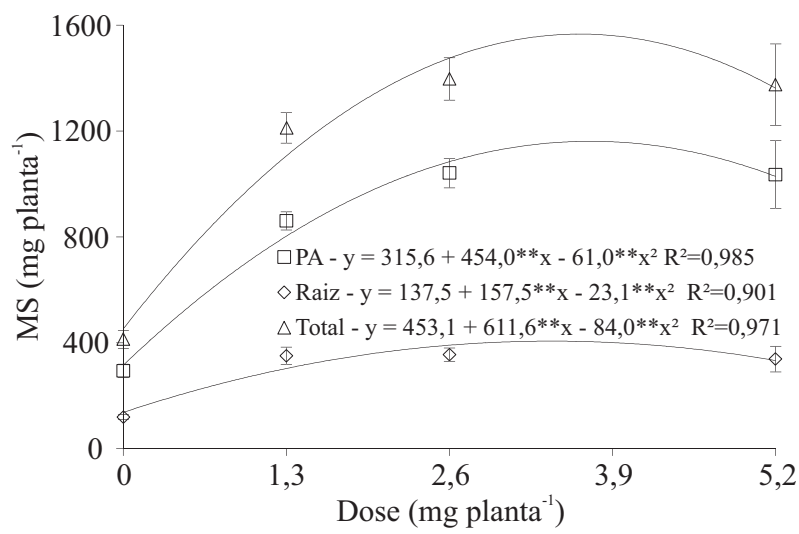

Figura 4 - Matéria seca da parte aérea (PA), raiz e total de mudas de eucalipto em função das doses de $\mathrm{P}$ determinada aos 90 dias. As barras significam o erro padrão da média do intervalo de dados.

Figure 4 - Shoot dry matter (PA), and root of eucalyptus according to the $P$ doses after 90 days. The bars indicate the standard deviation of the data interval.

Por fazer parte de vários processos metabólicos, doses reduzidas de $\mathrm{P}$ proporcionaram menor desenvolvimento das mudas, porém as doses muito elevadas prejudicam seu desenvolvimento. Segundo Furtini Neto et al. (1996), algumas espécies parecem não apresentar mecanismo efetivo para evitar "consumo de luxo" de P, levando a toxicidade. Outros trabalhos também evidenciaram o aumento da matéria seca, com a adubação fosfatada, em mudas clonais do híbrido Eucalyptus urograndis (AVILA, 2008).

As mudas que não receberam adubação fosfatada apresentaram baixo percentual de aproveitamento: $64 \%$. A dose estimada de $\mathrm{P}$ que resultou no maior percentual de enraizamento foi a de 3,9 mg planta ${ }^{-1}$, garantindo que $98 \%$ das estacas plantadas formassem mudas aptas para ir para o campo (Figura 5). A adubação fosfatada balanceada pode tornar mais eficiente o processo de produção de mudas, reduzindo em mais de $30 \%$ as perdas, diminuindo assim o custo por unidade produzida.

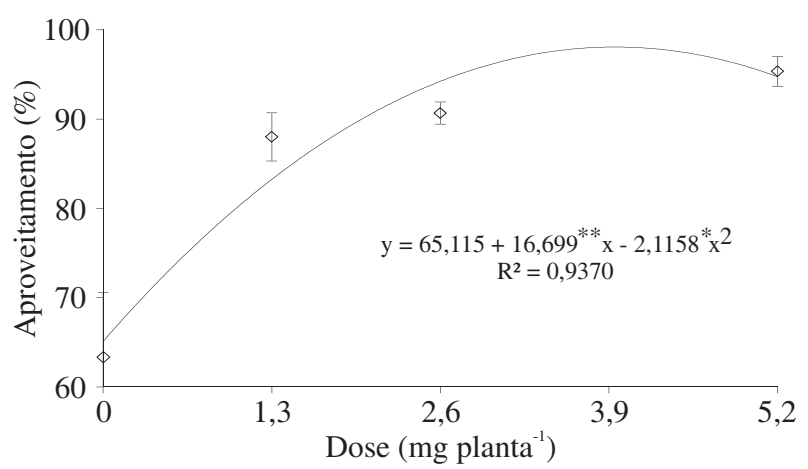

Figura 5 - Percentual de aproveitamento das mudas de eucalipto em função de doses de P. As barras significam o erro padrão da média do intervalo de dados.

Figure 5 - Percentage of utilization of eucalyptus seedlings as a function of doses of $P$. The bars indicate the standard deviation of the data interval.

\subsubsection{Características nutricionais}

As doses de P não influenciaram significativamente as concentrações de $\mathrm{S}$ e $\mathrm{Mn}$ na parte aérea das mudas. Para o N, houve aumento significativo com o aumento das doses de $\mathrm{P}$, tendo seu comportamento melhor representado por uma equação quadrática. A dose de $\mathrm{P}$ que resultou na maior concentração de $\mathrm{N}$ na parte aérea foi a máxima aplicada (5,2 mg planta $\left.{ }^{-1}\right)$, apresentando ainda tendência de crescimento a partir dessa dose (Figura 6). Esse fato explica-se, pela interação sinérgica entre o $\mathrm{P}$ e o $\mathrm{N}$ (ARAÚJO; MACHADO, 2006). A mesma tendência de crescimento para o $\mathrm{N}$ em função das aplicações de $\mathrm{P}$ foi observada por Neves et al. (1990), os quais relataram que a resposta das mudas ao $\mathrm{N}$ é dependente, em grau variável, de um adequado suprimento de $\mathrm{P}$.

Cerne, Lavras, v. 19, n. 4, p. 535-543, out./dez. 2013 


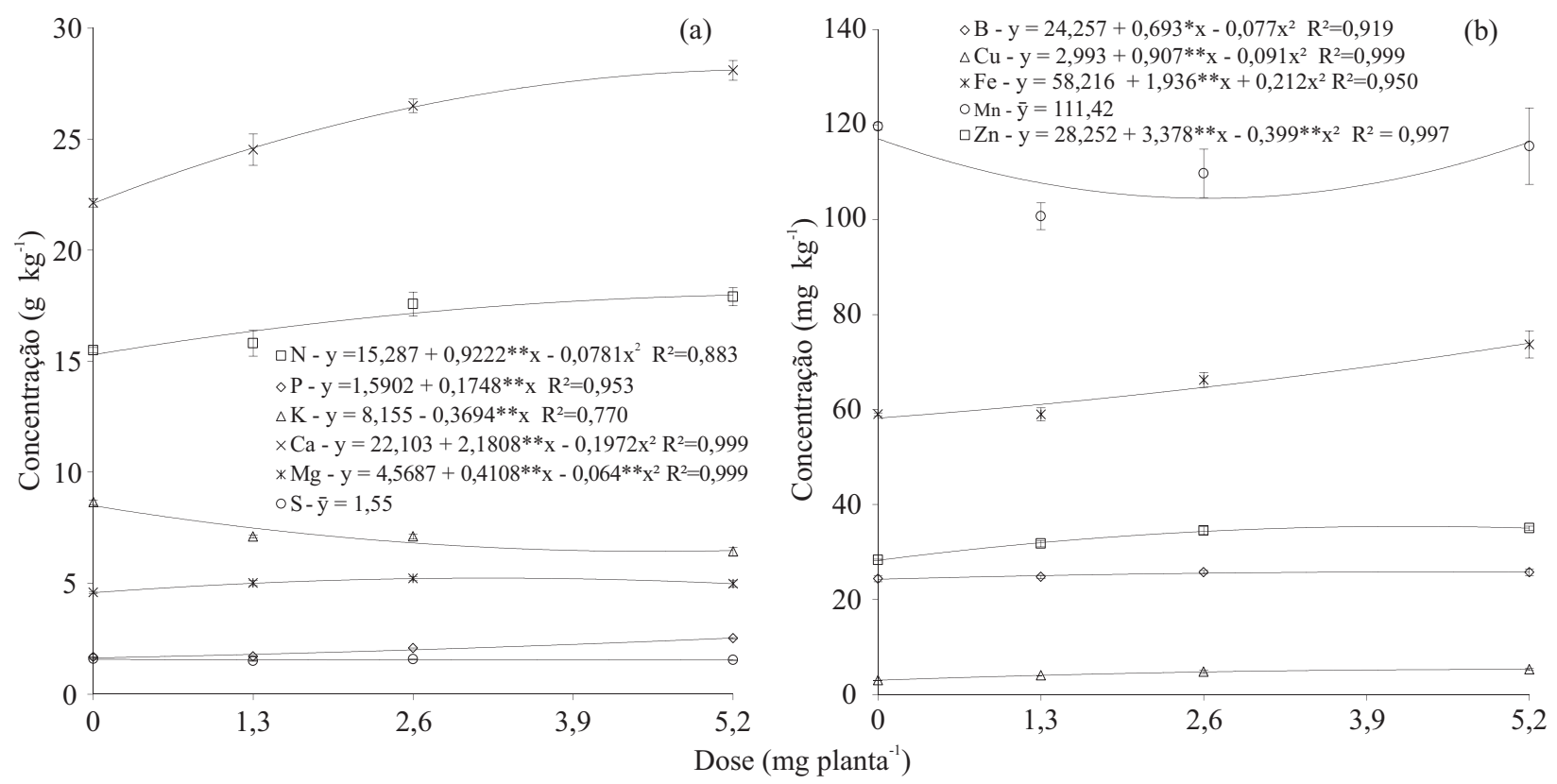

Figura 6 - Concentração de macro (a) e micronutrientes (b) na parte aérea de mudas de eucalipto em função de dose de P. As barras significam o erro padrão da média do intervalo de dados.

Figure 6-Concentration of macro (a) and micronutrients (b) in the shoots of eucalyptus as a function of doses of P. The bars idicate the standard deviation of the data interval.

Ocorreu aumento linear da concentração de P na parte aérea com o aumento das doses aplicadas. Fato que confirma a ausência de um mecanismo que evite o "consumo de luxo" de P por plantas de eucalipto. A concentração de $\mathrm{K}$ na parte aérea foi inversamente proporcional as doses de $\mathrm{P}$ aplicadas. As concentrações de $\mathrm{Ca}, \mathrm{Mg}, \mathrm{B}, \mathrm{Cu}, \mathrm{Fe}$ e $\mathrm{Zn}$ tendem a ser maiores com as doses de 5,$2 ; 3,2 ; 4,5 ; 5,0 ; 4,6$ e 4,2 $\mathrm{mg}_{\text {planta- }}{ }^{-1}$ respectivamente (Figura 6).

Com a aplicação de doses crescentes de $\mathrm{P}$, houve resposta da planta em termos de acúmulo de macro e micronutrientes. Os maiores acúmulos de $\mathrm{N}, \mathrm{P}, \mathrm{K}, \mathrm{Ca}$, $\mathrm{Mg}, \mathrm{S}, \mathrm{B}, \mathrm{Cu}, \mathrm{Fe}, \mathrm{Mn}$ e $\mathrm{Zn}$ foram obtidos com as doses estimadas de 3,$9 ; 4,9 ; 3,5 ; 4,0 ; 3,7 ; 3,7 ; 3,7 ; 3,8 ; 4,3 ; 4,1$ e 3,9 mg planta ${ }^{-1}$ de P, respectivamente (Figura 7). Nesse caso, as plantas responderam à aplicação de $\mathrm{P}$ com o incremento inicial de acúmulo dos nutrientes estudados e, a partir de doses maiores, a resposta à adubação passou a decrescer. A diminuição do acúmulo desses nutrientes na parte aérea das mudas deve-se ao fato de que, em doses maiores de $\mathrm{P}$, o crescimento das mudas foi comprometido, como verificado nas avaliações realizadas de altura, diâmetro e massa seca (ver item 3.1.1).

Cerne, Lavras, v. 19, n. 4, p. 535-543, out./dez. 2013

\subsection{Desenvolvimento e qualidade das mudas no campo}

O percentual de sobrevivência das mudas no campo em função das doses de $\mathrm{P}$ aplicadas foi representado siginificativamente $(\mathrm{p}<0,05)$ por uma equação quadrática, sendo a dose estimada de $3,8 \mathrm{mg}$ planta $^{-1}$ que resultou em maior percentual de sobrevivência (98\%) (Figura 8). Esta também foi a dose que proporcionou maior massa seca sistema radicular, confirmando a relação positiva existente entre o desenvolvimento do sistema radicular e o percentual de sobrevivência das mudas no campo, pois mudas com sistema radicular mais desenvolvido tem maior capacidade de absorção de água e nutrientes, resistindo, assim, ao estresse do plantio (MAFIA et al., 2005).

$\mathrm{O}$ aumento da porcentagem de sobrevivência decorre do uso de mudas de melhor padrão de qualidade, tornando, assim, dispensável o replantio, dada à pequena taxa de mortalidade que foi verificada. As mudas que não receberam adubação fosfatada apresentaram baixos percentuais de sobrevivência no campo (70\%). Esse fato não é desejado, visto que o replantio é uma atividade onerosa, e também gera uma condição de competição desfavorável, podendo trazer desuniformidade ao plantio e surgimento de plantas suprimidas (ALFENAS et al., 2004). 

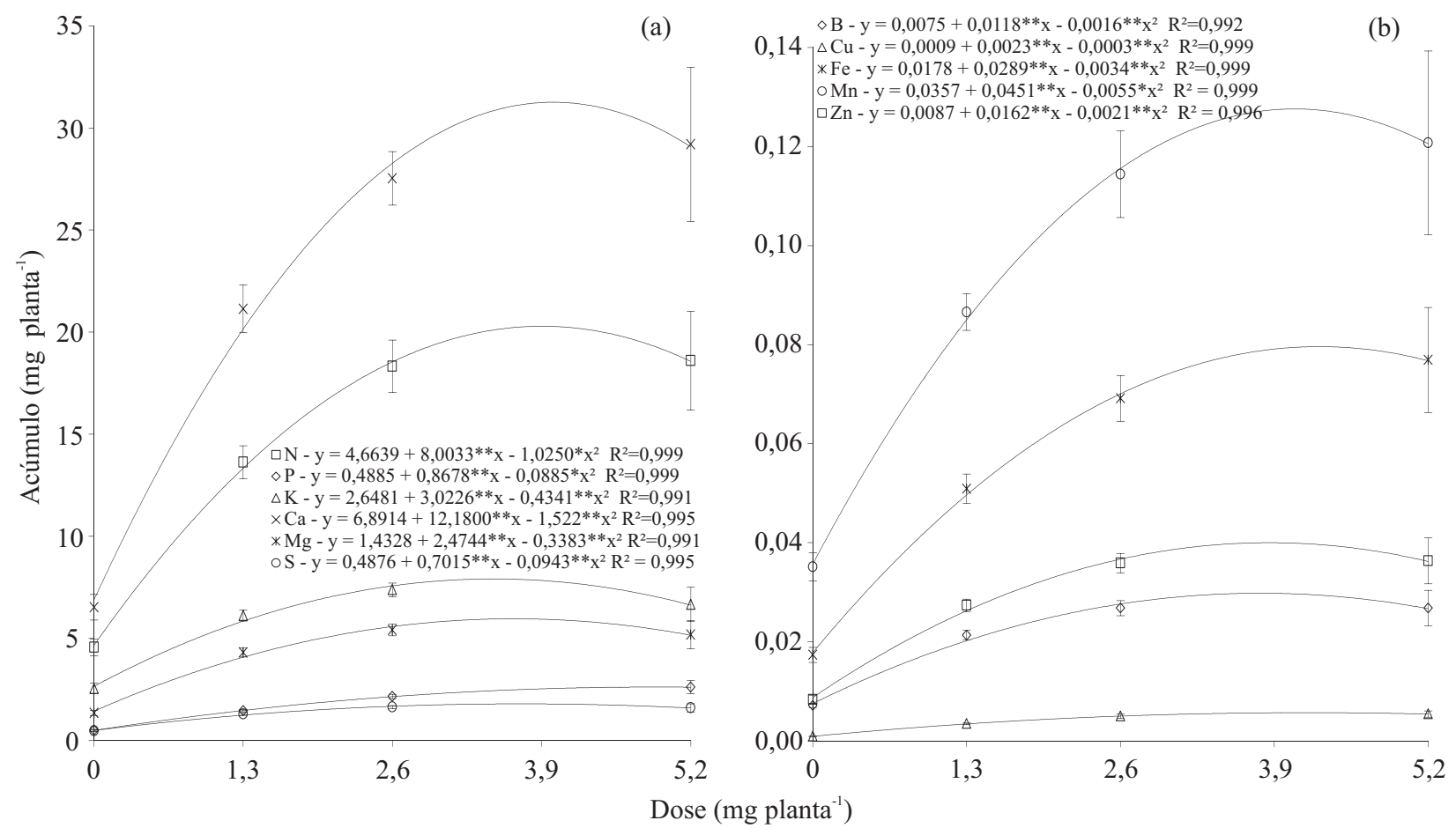

Figura 7 - Acúmulo de macro (a) e micronutrientes (b) na parte aérea de mudas de eucalipto em função de dose de P. As barras significam o erro padrão da média do intervalo de dados.

Figure 7-Accumulation of macro (a) and micronutrients (b) in the shoots of eucalyptus as a function of doses of P. The bars indicate the standard deviation of the data interval.

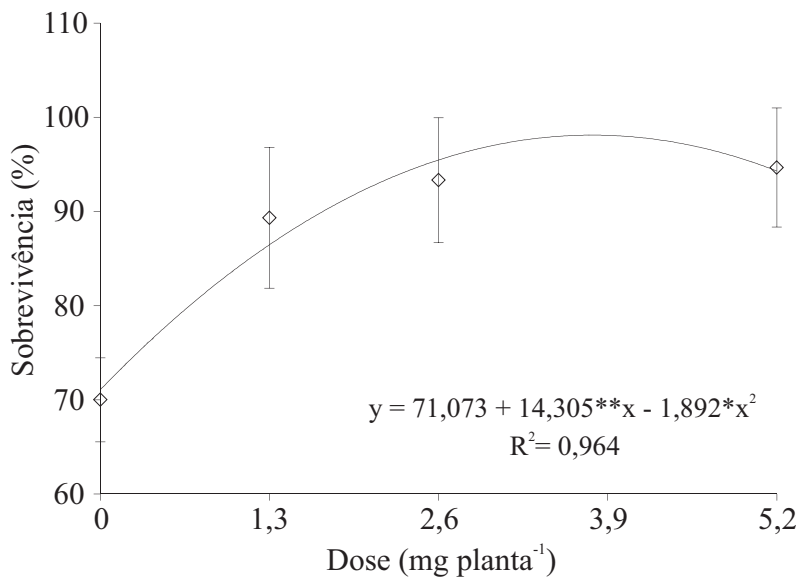

Figura 8 - Percentual de sobrevivência das mudas no campo em função das doses de $\mathrm{P}$ determinado 30 dias após o plantio no campo. As barras significam o erro padrão da média do intervalo de dados.

Figure 8 -Percentage survival of seedlings in the field as a function of phosphorus doses, 30 days after planting in the field. The bars indicate the standard deviation of the data interval.
Para o desenvolvimento inicial das mudas no campo não houve diferenças siginificativas em função das diferentes doses de $\mathrm{P}$. As mudas que não receberam $\mathrm{P}$ e sobreviveram no campo recuperaram-se e apresentaram desenvolvimento normal pois foi realizada a adubação de plantio com fosfato solúvel. A média de altura de planta e do diâmetro a altura do colo aos três meses, após o plantio foram de $98 \mathrm{~cm}$ e $11 \mathrm{~mm}$, respectivamente.

\section{CONCLUSÕES}

Para a obtenção de mudas de qualidade em condiçoes semelhantes a desse experimento, devem ser utilizadas doses de $\mathrm{P}$ na faixa de 3,6 a 3,8 $\mathrm{mg}_{\text {planta }}{ }^{-1}$.

$\mathrm{O} P$ tem efeito positivo no crescimento e na qualidade de muda de eucalipto, porém doses superiores a $4 \mathrm{mg}$ planta $^{-1}$ prejudicam o desenvolvimento e a qualidade das mudas de eucalipto.

A aplicação de $3,8 \mathrm{mg}$ planta $^{-1}$ de $\mathrm{P}$, na fase de produção de mudas de eucalipto, eleva em $30 \%$ seu percentual de sobrevivência no campo.

Cerne, Lavras, v. 19, n. 4, p. 535-543, out./dez. 2013 


\section{REFERÊNCIAS}

ALFENAS, A. C.; ZAUZA, E. A. V.; MAFIA, R. G.; ASSIS, T. F. Clonagem e doenças do eucalipto. Viçosa, MG: UFV, 2004. $442 \mathrm{p}$.

ARAÚJO, A. P.; MACHADO, C. T. T. Fósforo. In: FERNANDES, M. S. (Ed.). Nutrição mineral de plantas. Viçosa, MG: Sociedade Brasileira de Ciência do Solo, 2006. p. 253-281.

ASSENHEIMER, A. Benefícios do uso de biossólidos como substratos na produção de mudas de espécies florestais.

Ambiência, Guarapuava, v. 5, n. 2, p. 321-330, 2009.

ASSOCIAÇÃO BRASILEIRA DE PRODUTORES DE FLORESTA PLANTADA. Anuário estatístico da Associação Brasileira de Produtores de Floresta Plantada, ano base 2010. Brasilia, 2011. 140 p.

AVILA, F. S. d'. Efeito do fósforo, nitrogênio e potássio na produção de mudas cloanis de eucalipto. 2008. 53 p. Dissertação (Mestrado em Ciência Florestal) - Universidade Federal de Viçosa, Viçosa, 2008.

CARNEIRO, J. G. A. Produção e controle de qualidade de mudas florestais. Curitiba: UFPR/FUPEF, 1995. 451 p.

CECONI, D. E.; POLETTO, I.; BRUN, E. J.; LOVATO, T. Crescimento de mudas de açoita-cavalo (Luehea divaricata mart.) sob influência da adubação fosfatada. Cerne, Lavras, v. 12, n. 3, p. 292-299, 2006.

CECONI, D. E.; POLETTO, I.; LOVATO, T.; MUNIZ, M. F. B. Exigência nutricional de mudas de erva-mate (Ilex paraguariensis A. St.-Hil.) à adubação fosfatada. Ciência Florestal, Santa Maria, v. 17, n. 1, p. 25-32, 2007.

CORRÊA, M. C. M.; PRADO, R. M.; NATALE, W.; PEREIRA, L.; BARBOSA, J. C. Resposta de mudas de goiabeira a doses e modos de aplicação de fertilizante fosfatado. Revista Brasileira de Fruticultura, Jaboticabal, v. 25, p. 164-169, 2003.

CRUZ, C. A. F.; PAIVA, H. N.; GOMES, K. C. O.; GUERRERO, C. R. A. Efeito de diferentes níveis de saturação por bases no desenvolvimento e qualidade de mudas de ipê

Cerne, Lavras, v. 19, n. 4, p. 535-543, out./dez. 2013 roxo (Tabebuia impetiginosa (Mart.) Standley). Revista Scientia Forestalis, Piracicaba, n. 66, p. 100-107, 2004.

FERREIRA, D. F. Sisvar versão 4.2. Lavras: DEX/UFLA, 2003.

FURTINI NETO, A. E.; BARROS, N. F.; GODOY, M. F.; NOVAIS, R. F. Eficiência nutricional de mudas de Eucalyptus em relação a fósforo. Revista Árvore, Viçosa, v. 20, n. 1, p. 17-28, jan./fev. 1996.

GOMES, J. M.; COUTO, L.; LEITE, H. G.; XAVIER, A.; GARCIA, S. L. R. Crescimento de mudas de Eucalyptus grandis em diferentes tamanhos de tubetes e fertização NPK. Revista Árvore, Viçosa, v. 27, n. 2, p. 113-127, mar./abr. 2003.

GONÇALVES, J. L. M.; WICHERT, M. C. P.; GAVA, J. L.; SERRANO, M. I. P. Soil fertility and growth of Eucalyptus grandis in Brazil under different residue management practices. In: NAMBIAR, E. K. (Ed.). Site management and productivity in tropical plantation forests. Bogor: CIFOR, 2008. p. 51-62.

GRACIANO, C.; GOYA, J. F.; FRANGI, J. L.; GUIAMENT, J. J. Fertilization with phosphorus increasis soil nitrogen absorption in young plants of Eucalyptus grandis. Forest Ecology and Management, Amsterdam, v. 236, p. 202-210, 2006.

MAFIA, R. G.; ALFENAS, A. C.; SIQUEIRA, L.; FERREIRA, E. M.; LEITE, H. G.; CAVALLAZZI, J. R. P. Critério técnico para determinação da idade ótima de mudas de eucalipto para plantio. Revista Árvore, Viçosa, v. 29, n. 6 , p. 947-953, nov./dez. 2005.

MALAVOLTA, E. Nutrição mineral. In: FERRI, M. G. (Ed.). Fisiologia vegetal. São Paulo: EPU, 1985. p. 97-116.

MALAVOLTA, E.; VITTI, G. C.; OLIVEIRA, S. A. Avaliação do estado nutricional das plantas: princípios e aplicações. 2. ed. Piracicaba: POTAFÓS, 1997. 315 p.

NEVES, J. C. L.; GOMES, J. M.; NOVAIS, R. F. Fertilização mineral de mudas de eucalipto. In: BARROS, N. F.; NOVAIS, R. F. (Ed.). Relação solo-eucalipto. Viçosa, MG: UFV, 1990. p. 100-124. 
RAIJ, B. van; CANTARELLA, H.; QUAGGIO, J. A.; FURLANI, A. M. C. Recomendações de adubação e calagem para o Estado de São Paulo. 2. ed. Campinas: Instituto Agronômico/ Fundação IAC, 1997. 285 p. (Boletim Técnico, 100).

SCHAWAMBACH, J.; FADANELLI, C.; FETT NETO, A. $\mathrm{G}$. Mineral nutrition and adventitious rooting in microcuttings of Eucalyptus globules. Tree Physiology, Victoria, v. 25, p. 487-494, 2005.

SCHUMACHER, M. V.; CECONI, D. E.; SANTANA, C. A. Influência de diferentes doses de fósforo no crescimento de mudas de angico-vermelho (Parapiptadenia rigida (Bentham) Brenan). Revista Árvore, Viçosa, v. 28, n. 1, p. 149-155, jan./ fev. 2004.

SILVA, M. R.; KLAR, A. E.; PASSOS, J. R. Efeitos do manejo hídrico e da aplicação de potássio nas características morfofisiológicas de mudas de Eucalyptus grandis W. (Hill ex. Maiden). Irriga, Botucatu, v. 9, n. 1, p. 31-40, 2004.

XAVIER, A.; WENDLING, I.; SILVA, R. L. Silvicultura clonal: princípios e técnicas. Viçosa, MG: UFV, 2009. 272 p.

Recebido: 3 de março de 2011; aceito: 24 de maio de 2013. 
